\title{
The effect of intraarticular triamcinolone acetonide on inflammation in knee osteoarthritis as assessed by Tc-99m HIG scintigraphy
}

\author{
Ilknur KARLIBEL ${ }^{1}$, Munir Kerim KARAKAYA ${ }^{2}$, Tayyar AKPINAR ${ }^{3}$
}

1 Department of Physicial Me dicine and Rehabilitation, University of Health Sciences Turkey Bursa Yu ksek Ihtisas Training and Research

Hos pital, Bursa, TURKEY

2 Physicial Medicine and Rehabilitation, Professor (Retired)

3 De partment of Nuclear Medicine, Me dical Faculty, Ul udag University, Bursa, TURKEY

\begin{abstract}
Aim: Our study aimed to evaluate the degree of response to intraarticular corticosteroid injection (IACSI) in patients with knee osteoarthritis using Tc-99m HIG scintigraphy and to investigate the relationship between changes in inflammatory activity and clinical and radiological findings.

Methods: The study included 50 knees of 25 patients with symptomatic bilateral knee OA according to American College of Rheumatology (ACR) criteria. The knee with synovitis was the patient group (Group $1, n=25)$. The knee without synovitis was the control group (Group 2, $n=25$ ). Synovial fluid aspiration was performed in the knee joint with synovitis. Subsequently, a suspension containing $1 \mathrm{ml}$ of TCA (40 $\mathrm{mg} / \mathrm{ml}$ ) was injected into the synovial cavity. The clinical status was evaluated according to the WOMAC Osteoarthrosis Index. Knee radiographs were evaluated according to the Kellgren and Lawrence criteria. The patients were administered Tc-99m polyclonal human immunoglobulin G (HIG) intravenously. Evaluations were performed before and four weeks after treatment.

Results: There was a significant difference between the two groups in all parameters except radiography when group 1 and group 2 were compared. There was a positive correlation between the Tc99m HIG scintigraphy score and all clinical parameters except the amount of effusion and radiography $(p<0.001)$. The study was completed with 20 patients. After treatment, a significant improvement was observed in all parameters of the 20 patients $(p<0.05)$. After treatment, all clinical parameters improved. The improvement in scintigraphy findings after treatment was variable. After the treatment, there was a positive correlation between the Tc99m HIG scintigraphy score and other clinical parameters except for joint swelling and radiography $(p<0.05)$. Also, there was a positive correlation between the rate of change in scintigraphy score and the WOMAC total pain score and WOMAC physical function score.

Conclusions: Our results showed that Tc99m-HIG scintigraphy was able to evaluate the response of IACSI to treatment in OA inflammation more effectively than clinical findings and did this independently of anatomic changes.
\end{abstract}

Keywords: Inflammation, Intraarticular Corticosteroids, Knee osteoarthritis, TC 99m HIG

Corresponding Author: llknur KARLIBEL karlibeli@hotmail.com

Received: July 23, 2021; Accepted:August 11, 2021; Published Online: August 30, 2021

Cite this article as: Karlibel, I. \& Akpinar, T. (2021). The effect of intraarticular triamcinolone acetonide on inflammation in knee osteoarthritis as assessed by Tc-99m HIG scintigraphy 2(3), 18-29. 


\section{Introduction}

Osteoarthritis (OA) is the most common chronic degenerative joint disease [1]. It is an important cause of morbidity and economic burden in the growing elderly population [2]. Despite the high prevalence of $\mathrm{OA}$, the pathogenetic mechanism is unclear. Previously, it was described as a non-inflammatory degenerative disease, but now the role of inflammation in the pathogenesis is mentioned. However, it is not clear where inflammation has its effect in the OA process [3]. The pathological phenomenon works by a complex mechanism in which anabolic and catabolic processes coexist in the structures forming the joint. Interactions within the cytokine network are held to be responsible for this situation. It is thought that synovial inflammation in OA develops as a result of a foreign body reaction to impaired cartilage products within the joint of synovial cells [4]. Synovitis can occur in the early stages of the disease, and its prevalence increases with the advanced disease stage $[5,6]$. In $\mathrm{OA}$, the synovium has been a key target for treatment. Intraarticular corticosteroid injections (IACSI), including triamcinolone acetonide (TCA), is often used to treat acute and chronic inflammatory conditions. The likely basic effect is the modulation of synovial inflammation [7]. It increases joint mobility by reducing joint effusion and pain in a short time after the intraarticular application [8]. However, the therapeutic efficacy of IACSI is relatively short-lasting, with clinically significant benefits only up to 4 weeks [9]. Studies investigating the response to long-release forms and repetitive injections investigate how long this effect can extend without a negative effect on cartilage $[10,11]$. The short-term effect is because the drug is delivered to the systemic circulation by the rapid flow out of the joint [7]. Studies in OA show conflicting results on clinical predictors of response to IACSI $[12,13]$. It has been suggested that the largest effect is seen in patients with evidence of inflammation on physical examination $[12,14]$. The main problem is the degree of response to treatment and the duration [15]. However, to the best of our knowledge, there are few studies examining the response to treatment quantitatively.

Polyclonal human immunoglobulin (HIG) scintigraphy has been proposed as a reliable and objective imaging method for joint inflammation $[16,17]$. The mechanism of HIG accumulation in the site of inflammation is not clear $[18,19]$. The following hypotheses have been proposed for the mechanism: increased vascular permeability [20], specific capture of IgG by receptors for immunoglobulins in inflammatory cells [21], binding to extracellular matrix proteins [22] and bacterial affinity [23]. Furthermore, authors emphasize the role of Tc-99m HIG in quantifying the severity of inflammation [22,24].

The aim of our study was to evaluate the degree of response to intraarticular corticosteroid injection in patients with knee osteoarthritis using Tc-99m HIG scintigraphy and to investigate the relationship between changes in inflammatory activity and clinical and radiological findings.

\section{Methods}

The study was carried out in the Department of Physical Medicine and Rehabilitation of Uludag University in accordance with the 1964 Helsinki declaration and comparable ethical standards. Local ethics committee approval was obtained. All patients were informed about the study, and their written informed consent was obtained.

\section{Patients}

The study included 50 knees of 25 patients with symptomatic bilateral knee $\mathrm{OA}$ according to American College of Rheumatology (ACR) criteria for more than six months, who did not show an adequate response 
to the use of paracetamol or traditional nonsteroidal anti-inflammatory drugs (NSAIDs), and who had clinically detected synovitis in at least one knee joint.

Patients with acute-chronic systemic infection, reactive arthritis, rheumatoid arthritis (RA), psoriatic arthritis, ankylosing spondylitis or arthritis due to inflammatory bowel disease, a history of infection in the index knee joint, clinical manifestations of active knee infection or with crystal disease of the index knee joint, a history of surgery, endocrine or metabolic disease, systemic disease (such as chronic renal failure, COPD, etc.) or malignant disease, and neurological or psychiatric disorders were excluded from the study. At the same time, cases were excluded from treatment if IACSI was administered in the previous three months, intraarticular therapy such as hyaluronic acid, platelet rich plasma (PRP) in the last one year, intravenous/intramuscular CS within three months or oral CS within 1 month.

\section{Clinical evaluation}

Clinical status was evaluated according to the Western Ontario McMaster Universities Osteoarthrosis Index (WOMAC) [25]. Pain (5 parameters), stiffness (2 parameters) and physical function (17 parameters) in the last week were scored using a Likert scale (in 5 categories). Local heat increase was evaluated as either present or absent. Joint sensitivity and joint effusion were evaluated according to a 0-3 point scale. Range of motion (flexion and extension) was measured with a goniometer.

\section{Radiologic Evaluation}

Anterior-posterior and lateral knee radiographs (in standing position) were evaluated according to the Kellgren and Lawrence criteria [26] by a blinded investigator to clinical and scintigraphy findings, and the knee osteoarthrosis was graded (stage 1 - 4).

\section{Scintigraphy Evaluation}

This was performed just before and four weeks after intraarticular injection. The patients were administered Tc-99m polyclonal Human immunoglobulin G intravenously (Technescan HIG, Mallinekrdt Medical, Holland), $15 \mathrm{Mci}$ (555 MBq), prepared in accordance with the manufacturer's instructions. Four hours after the injection, a gamma camera (Starcam 3200 XRT, General Electric, Milwaukee, Wi, USA) and two knee planar imagings were performed on the front, right side and left side projections. The images were evaluated blinded to clinical and radiological information by a specialist in nuclear medicine. Results were scored between 0 and 3 (0: no involvement, 1: minimal activity increase, 2 : moderate activity increase (less than the intravascular environmental activity), 3: increased pronounced activity (equal to or greater than the intravascular environmental activity). No side effects related to radiopharmaceutical products were observed.

While the patient was in the supine position, synovial fluid aspiration was performed in the knee joint with synovitis under aseptic conditions through a medial approach. No ultrasound guidance was needed for the application. The amount of effusion obtained was recorded. Subsequently, a suspension containing $1 \mathrm{ml}$ of TCA $(40 \mathrm{mg} / \mathrm{ml})$ was injected into the synovial cavity. Patients were evaluated clinically and scintigraphically before and four weeks after treatment.

\section{Statistical analysis}

IBM SPSS 22.0 statistics software was used to analyse data obtained through the study. In the assessment of the data, Chi-square (c2) test was used to compare categorical data. Descriptive statistical methods (percentage, mean, standard deviation, median, minmax) were used to assess the study data. Shapiro-Wilk 
test was used to assess whether or not the data were normally distributed. Independent Samples t-test (ttest for independent groups) was used in betweengroup comparisons when variables were normally distributed. When a normal distribution was not found, Wilcoxon signed-rank test for intra-group comparisons and Mann Whitney $U$ test for inter-group comparisons were used. Values with a probability of $(P) a<0.05$ was accepted as significant.

\section{Results}

50 knees of 25 patients with bilateral gonarthrosis, having $\mathrm{OA}$ definition according to ACR criteria, were table 1. included in the study. 25 of the 50 painful knee joints with clinical swelling and temperature increase were included in the patient group (Group $1, \mathrm{n}=25$ ). Clinically, the non-synovitis knee was the control group (Group 2, $\mathrm{n}=25$ ). The mean age of the patients was $58.76 \pm 7.40$ (49-79), 5 were men (20\%) and 20 (80\%) were female. The average pain duration of patients for both knee joints was $5.06 \pm 3.75$ (1-15) years, and the swelling time in a knee was $45.3 \pm$ 40.07 (5-150) days. Clinical, radiographic and demographic characteristics of patients are shown in

Table 1. Clinical, radiographic and demographic characteristics of patients

\begin{tabular}{|c|c|}
\hline$n=25$ & \\
\hline Age $(\text { year })^{a}$ & $58.76 \pm 7.40(49-79)$ \\
\hline Gender $\%$ & $20 \%$ male; $80 \%$ female \\
\hline $\operatorname{BMI}\left(\mathrm{Kg} / \mathrm{m}^{2}\right)^{\text {a }}$ & $30.44 \pm 3.53(25.96-41.33)$ \\
\hline Pain duration (y ear) a & $5.06 \pm 3.75(1-5)$ \\
\hline Joint swelling duration (day) ${ }^{a}$ & $45.40 \pm 40.07(5-150)$ \\
\hline \multicolumn{2}{|l|}{ Radiography (right knee/ left knee) (n) } \\
\hline Stage 1 & $7 / 6$ \\
\hline Stage 2 & $13 / 15$ \\
\hline Stage 3 & $4 / 3$ \\
\hline Stage 4 & $1 / 1$ \\
\hline
\end{tabular}

Median $\pm S D$ (range of distribution) ${ }^{a}$, BMI: Body Mass Index, Radiography: Kellgren-Lawrence radiographic staging,

When evaluated before treatment, all clinical and scintigraphy parameters were significantly different in the patient group compared to the control group ( $p$
$<0.001$ ), but there was no significant difference between the two groups in terms of radiographic scores ( $p$ >0.05) (Table 2). 
Table 2. Pre-treatment values of Group 1 and Group 2

\begin{tabular}{|l|c|c|c|}
\hline & Group 1 (n=25) & Group 2(n=25) & p \\
\hline WOM AC Pain Total & $17.36 \pm 3.21$ & $6.04 \pm 1.67$ & $<0.001$ \\
\hline Joint swelling & $1.88 \pm 0.83$ & $0.12 \pm 0.33$ & $<0.001$ \\
\hline Joint sensitivity & $1.84 \pm 0.47$ & $1.96 \pm 0.73$ & $>0.05$ \\
\hline Radiography & $1.96 \pm 0.78$ & $0.32 \pm 0.62$ & $<0.001$ \\
\hline Tc-99m HIG & $2.36 \pm 0.70$ & 0.001 \\
\hline
\end{tabular}

Median $\pm S D$ (range of distribution), $p<0.05$ was considered significant, WOMAC: W estern Ontario McMaster Universities Osteoart hrosis Index, Radiography: Kellgren-Lawrence radiog raphic staging, Tc-99m HIG: Technetium-99m Human Immunoglobulin scintigraphy score.

When the patients were evaluated before treatment $(n$ $=25$ ), there was a positive correlation between the Tc99m HIG scintigraphy score and all clinical parameters except the amount of effusion $(p<0.001)$. There was no correlation between radiography and scintigraphy involvement ( $p>0.05)$ (Table 3).

Table 3. S cintigraphy scores and clinical and radiographic parameters of Group 1 patients

\begin{tabular}{|c|c|c|c|c|}
\hline \multicolumn{5}{|c|}{ Tc-99m HIG } \\
\hline & \multicolumn{2}{|c|}{ Before Treatment $(n=25)$} & \multicolumn{2}{|c|}{ After Treatment $(n=20)$} \\
\hline & $\mathrm{r}$ & $\mathrm{p}$ & $\mathrm{r}$ & $\mathrm{P}$ \\
\hline WOM AC Pain Total & 0.9613 & $<0.001$ & 0.6807 & $<0.001$ \\
\hline WOM AC stiffness Total & 0.6550 & $<0.001$ & 0.5272 & $<0.05$ \\
\hline WOM AC phy sical function & 0.9100 & $<0.001$ & 0.6029 & $<0.01$ \\
\hline Joint swelling & 0.7945 & $<0.001$ & 0.3327 & $<0.05$ \\
\hline Joint sensitivity & 0.8249 & $<0.001$ & 0.2199 & $>0.05$ \\
\hline joint temperature & 0.8429 & $<0.001$ & 0.3182 & $<0.05$ \\
\hline Volume of aspirated fluid (ml) & 0.3737 & $>0.05$ & - & - \\
\hline Radiography & 0.1214 & $>0.05$ & -0.0355 & $>0.05$ \\
\hline
\end{tabular}

p<0.05 was considered significant, W OMAC: Western Ontario McMaster Universities Osteoarthrosis Index, ml: millilitre, Radiography: Kellgren-Lawrence radiographic staging, Tc99m HIG: Technetium-99m Human Immunoglobulin scintigraphy score.

Five of the 25 patients who underwent IACSI did not come to the control visit. The study was completed with 20 patients (Figure 1). After treatment, a significant improvement was observed in all parameters of the 20 patients $(p<0.05)$ (Table 4$)$. 
Table 4. Clinical and scintigraphy values of patients in Group 1 before and after treatment

\begin{tabular}{|c|c|c|c|}
\hline $\mathrm{n}=20$ & Before Treatment & After Treatment & \\
\hline & Median \pm SD & Median \pm SD & $\mathrm{p}$ \\
\hline WOM AC Pain Total & $17.36 \pm 3.21$ & $6.86 \pm 2.41$ & $<0.001$ \\
\hline WOM AC stiffness Total & $6.12 \pm 1.18$ & $3.17 \pm 0.29$ & $<0.001$ \\
\hline WOM AC phy sical function & $58.64 \pm 12.18$ & $27.38 \pm 11.39$ & $<0.001$ \\
\hline Joint sensitivity & $1.84 \pm 0.47$ & $0.13 \pm 0.34$ & $<0.001$ \\
\hline Joint swelling & $1.88 \pm 0.83$ & $0.26 \pm 0.54$ & $<0.001$ \\
\hline ROM (flexion) & $119.40 \pm 13.02$ & $136.30 \pm 7.72$ & $<0.001$ \\
\hline ROM (extension) & $-1.80 \pm 2.84$ & $-0.87 \pm 1.94$ & 0.05 \\
\hline Tc-99m HIG & $2.36 \pm 0.70$ & $0.95 \pm 1.05$ & $<0.001$ \\
\hline
\end{tabular}

p<0.05 was considered significant, W OMAC: Western Ontario McMaster Universities Osteoarthrosis Index, ROM: Range of motion, Tc-99m HIG: Technetium-99m Human Immunoglobulin scintigraphy score. 
Figure 1. Flow diagram

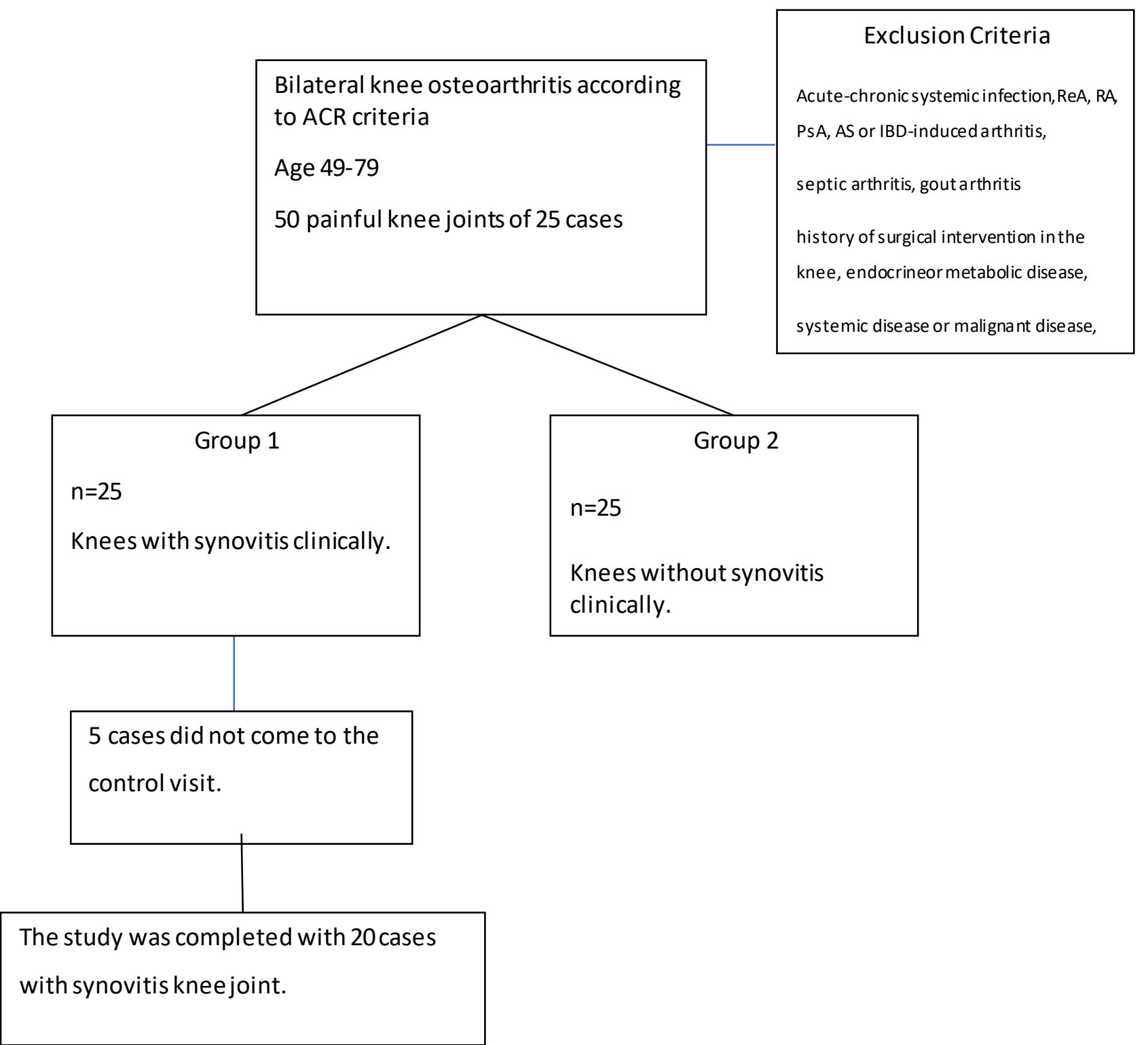

ReA: Reactive Arthritis, RA: Rheumatoid Arthritis, PsA: Psoriatic Arthritis, AS: Ankylosing Spondylitis, IBD: Inflammatory Bo wel Disease.

This improvement was $100 \%$ in clinical parameters. However, after treatment, scintigraphy findings were decreased in 16 patients (80\%), increased in 1 patient (5\%) and no change in 3 patients (15\%).

After the treatment, there was no correlation between Tc99m HIG scintigraphy score and joint sensitivity and radiographic parameters $(p>0.05)$. There was a positive correlation between the Tc99m HIG scintigraphy score and other clinical parameters ( $p$ $<0.05$ ) (Table 3).

After treatment, the results of the correlation analysis between the rate of change in scintigraphy parameters and the rate of change in clinical parameters are shown in Table 5. 
Table 5. Rates of change from baseline after treatment in Group 1

\begin{tabular}{|c|c|c|}
\hline \multirow[t]{2}{*}{$\mathrm{n}=20$} & \multicolumn{2}{|c|}{ Tc-99m HIG } \\
\hline & $\mathrm{r}$ & $\mathrm{p}$ \\
\hline WOMAC Pain Total & 0.5996 & $<0.01$ \\
\hline WOMAC stiffness Total & 0.2048 & $>0.05$ \\
\hline WOM AC phy sical function & 0.6260 & $<0.01$ \\
\hline Joint sensitivity & 0.0354 & $>0.05$ \\
\hline Joint swelling & 0.0115 & $>0.05$ \\
\hline joint temperature & 0.4062 & $>0.05$ \\
\hline ROM (flexion) & -0.2132 & $>0.05$ \\
\hline ROM (extension) & -0.2557 & $>0.05$ \\
\hline
\end{tabular}

p<0.05 was considered significant, W OMAC: Western Ontario McMaster Universities Osteoarthrosis Index, ROM: Range of motion, Tc-99m HIG: Technetium-99m Human Immunoglobulin scintigraphy score.

There was a positive correlation between the rate of change in scintigraphy score and WOMAC total pain score and WOMAC physical function score.

\section{Discussion}

Our results confirmed the benefit of IACS in symptomatic knee OA. The results of our study showed that the improvement in inflammatory activity assessed by Tc-99m HIG scintigraphy after intraarticular corticosteroid injection in knee osteoarthritis was lower than clinical improvement. While there was a correlation between scintigraphy improvement and pain and physical function, there was no significant relationship between scintigraphy improvement and improvement in other clinical parameters.
Intraarticular steroid injection is a recommended treatment option in OA. Many studies have shown that IACSI provides a significant short-term improvement in pain in OA [27]. Experimental OA models show that low-dose CSs reduce cartilage lesions and size, severity and progression of osteophytes [28]. IACSI shows a chondroprotective effect by suppressing the synthesis of stromelysin and facilitating lubrication [29]. Clinical studies have contradictory results on clinical markers of response to IA corticosteroids in $O A$. In clinical trials, clinical effusion has been shown to be a marker of response to IACSI [12]. Another study advocated that the improvement in pain and synovial effusion in the first month after IACSI may be an indicator of a one-year response [30]. In clinical practice, IACSI provides an improvement in pain and functional capacity due to the rapidly emerging antiinflammatory effect [31]. In contrast, two studies were unable to identify a marker indicating the response to 
treatment $[12,13]$. One study in RA patients found a decrease in activity in all the assessments performed clinically, histologically and with Tc99m HIG scintigraphy 14 months after IACSI. Based on this, Tc99m HIG scintigraphy has been suggested to reflect well the individual changes of patients. At the same time, in this study, the improvement in both clinical and scintigraphy parameters after IACSI were similar [32]. In contrast, in our study, although we found improvement in all clinical parameters after IACSI, the improvement in scintigraphy parameters was lower. We found a positive correlation between scintigraphy healing and total pain and physical function, but we could not find a relationship between scintigraphy parameters and other clinical parameters. This is because while the subjective findings showing inflammation such as morning stiffness, swelling, susceptibility and heat increase may appear completely healed, perhaps mild inflammation can continue. This situation may require long-term and recurrent injections of IACSI. In fact, Raynauld et al., in their study, found significant improvement in ROM with long-term and repeated injections of IACSI and found a lower improvement in pain, but found no difference in anatomic progression [33]. In addition, it has been stated that the duration of the anti-inflammatory effect can be prolonged with long release forms of TCA [34]. But no difference was found between doses of $40 \mathrm{mg}$ and $80 \mathrm{mg}$ [35]. In addition, there was a history of recurrent effusion in 3 patients with no improvement in scintigraphy involvement despite clinical improvement after treatment. In addition, one patient had increased scintigraphy involvement. In these patients, we thought that synovitis may become chronic and may lead to synovial hypertrophy, or treatment may be ineffective. In fact, Chao et al. found that patients with synovial hypertrophy detected by ultrasound did not achieve long-term benefit from IACSI [3].
Tc99m HICG is a suitable and reliable method for detecting inflammation of the musculoskeletal system. Many studies of Tc99m HICG have been done [36]. In addition, Tc99m HIG scintigraphy was found to be useful for measuring the severity of inflammation in RA. It was also shown that there was a positive relationship between clinical and scintigraphy findings [37]. It has been emphasised that synovial imaging depends on the inflammatory phenomenon rather than the source of inflammation [38]. De Bois et al. found that the correlation between scintigraphy findings and joint swelling was higher than with pain, and that joint swelling was the main predictive value for Tc99m HIG [39]. In our study, we found a high correlation between Tc99m HIG scintigraphy scores and all clinical scores (except the amount of effusion), in accordance with the literature, based on pre-treatment values. These results suggest that clinically determined joint inflammation is supported scintigraphically, but the synovial fluid itself does not determine HIG accumulation alone. In fact, Jamar et al. found that patients with RA, PSA and OA had joint involvement with HIG scintigraphy, but they did not have involvement in the joints of patients with severe chondropathy and hydrarthrosis. This result supports our results [38].

In our study, there was no correlation between radiographic scores and clinical or scintigraphy scores, in accordance with the literature [39]. We can conclude that scintigraphy involvement in $\mathrm{OA}$ and joint inflammation are independent of anatomic changes.

Studies have shown that the amount of effusion, local heat increase, synovial thickening, sensitivity, anxiety and depression score, Health Assessment Questionnaire (HAQ) score, range of motion and quadriceps muscle power can play a key role in the prediction of IACSI response. However, none was seen to be an important predictor of patient response 
$[12,13]$. The methods used to evaluate local inflammation in $\mathrm{OA}$ were found to be insufficient.

The most important limitation of our study was the small number of cases. There is a need for randomised controlled studies comparing this method with other diagnostic techniques such as ultrasound in detecting inflammation in osteoarthritis.

Our results have shown that the response to treatment of inflammation in $\mathrm{OA}$ can be evaluated more effectively by Tc99m-HIG scintigraphy compared to clinical findings, and this is independent of anatomic changes. Our study suggests that Tc99m-HIG scintigraphy may be a predictive factor for IACSI for the inflammation in $\mathrm{OA}$. We believe that this technique may be an alternative quantitative method for evaluating treatment regimens for joint inflammation in $\mathrm{OA}$

\section{Acknowledgements}

We commemorate Prof. Dr Münir Kerim Karakaya, who led us in the planning and elaboration of the study but who lost his life during the publication stage.

\section{Conflict of interest}

The authors declare that they have no conflict of interest.

\section{References}

1. Bijlsma JWJ, Berenbaum F, Lafeber FPJG. Osteoarthritis: an update with relevance for clinical practice. Lancet. 2011;18;377(9783):2115-26. doi: 10.1016/S0140-6736 (11) 60243-2.

2. Lawrence RC, Felson DT, Helmick CG, at al. Estimates of the prevalence of arthritis and other rheumatic conditions in the United States. Part II. National Arthritis Data Workgroup Arthritis Rheum. 2008;58(1):26-35. doi: $10.1002 /$ art.23176

3. Chao J, Wu C, Sun B, et al. Inflammatory characteristics on ultrasound predict poorer long-term response to intraarticular corticosteroid injections in knee osteoarthritis. JRheumatol. 2010;37(3):650-5. 10.3899/jrheum.090575

4. Berenbaum F. Osteoarthritis as an inflammatory disease (osteoarthritis is not osteoarthrosis!). Osteoarthritis Cartilage. 2013;21(1):16-21. doi: 10.1016/j.joca. 2012.11.012.

5. Benito $M J$, Veale $D J$, FitzGerald $O$, van den Berg WB, Bresnihan B. Synovial tissue inflammation in early and late osteoarthritis. Ann Rheum Dis. 2005; 64(9):1263-7.

6. Krasnokutsky S, Belitskaya-Lévy I, Bencardino $\mathrm{J}$, et al. Quantitative magnetic resonance imaging evidence of synovial proliferation is associated with radiographic severity of knee osteoarthritis.

Arthritis

Rheum. 2011;63(10):2983-91.

doi: $10.1002 / a r t .30471$.

7. Paik J, Duggan ST, Keam SJ. Triamcinolone Acetonide Extended-Release: A Review in Osteoarthritis Pain of the Knee . Drugs. 2019;79(4):455-462. doi: $10.1007 / \mathrm{s} 40265-019-01083-3$

8. Rozental TD, Sculco TP. Intra-articular corticosteroids: an updated overview. Am J Orthop (Belle Mead NJ) 2000; 29: 18-23

9. Da Costa BR, Hari R, Juni P. Intra-articular Corticosteroids for Osteoarthritis of the Knee JAMA. 2016; 316 (24): 2671-2.

10. Langworthy MJ, Conaghan PG, Ruane JJ, et al. Efficacy of Triamcinolone Acetonide ExtendedRelease in Participants with Unilateral Knee Osteoarthritis: A Post Hoc Analysis. Adv Ther. 2019 ;9. doi: 10.1007/s12325-019-00944-3. 
11. Spitzer AI, Richmond JC, Kraus VB, et al. Safety and Efficacy of Repeat Administration of Triamcinolone Acetonide Extended-release in Osteoarthritis of the Knee: A Phase 3b, Openlabel Study. Rheumatol Ther. 2019; 6 (1): 109-124. doi: 10.1007 / s40744-019-0140-z.

12. Coll S, Matabosch X, Llorente-Onaindia J, et al. Elimination profile of triamcinolone hexacetonide and its metabolites in human urine and plasma after a single intra-articular administration. Drug Test Anal. 2019 Nov; 11(11-12):1589-1600. 10.1002/dta.2614.

13. Heidari P, Heidari B, Babaei M. Efficacy and predictive factors of response to intra-articular corticosteroids in knee osteoarthritis. Reumatologia. 2020;58(6):424-435. doi: 10.5114/reum.2020.102008.

14. O'Neill TW, Parkes MJ, Maricar N, Marjanovic EJ, Synovial tissue volume: a treatment target in knee osteoarthritis (OA). Ann Rheum Dis. 2016; 75(1):84-90. doi: 10.1136 / annrheumdis-2014-206927

15. Calvet J, Orellana C, Galisteo C, et al. Clinical and ultrasonographic features associated to response to intraarticular corticosteroid injection. A one year follow up prospective cohort study in knee osteoarthritis patient with joint effusion. PLoS One. 2018;19;13(1): e0191342. doi: 10.1371/journal.pone.0191342.

16. Popma JW, Snel FW, Haagsma CJ, et al. Comparison of 2 Dosages of Intraarticular Triamcinolone for the Treatment of Knee Arthritis: Results of a 12-week Randomized Controlled Clinical Trial. J Rheumatol. 2015;42(10):1865-8.

doi: 10.3899/jrheum. 141630.

17. Kacar G, Kacar C, Gungor F. The Agreement Between Blood Pool - Delayed Bone Scintigraphy and Tc-99m Human Immunoglobulin G (HIG) Scintigraphy in the Determination of the Presence and Severity of Inflammatory Arthritis. Mol Imaging Radionucl Ther. 2011;20(2):45-51. doi: 10.4274/MIRT.24.

18. Ozdoğan O, Değirmenci B, Senocak $O$, et al. Tc-99m HIG Scintigraphy in Detection of Active Inflammation in Ankylosing Spondylitis. Mol Imaging Radionud Ther. 2011;20(2):52-8. doi: $10.4274 /$ MIRT.21.

19. Bois MHW, Pauwels EKJ. Arthritis: current status of scintigraphy and future trends. In:
Murray IPJ, Ell PJ, editors. Nuclear Medicine in Clinical Diagnosis and Treatment. New York: Churchill Livingstone; 1994. pp. 1041-1054

20. Bois MHW, Pauwels EKJ, Breedveld FC. New agents for scintigraphy in rheumatoid arthritis. Eur J Nucl Med. 1995; 22:1339-1346.

21. Morrell EM, Tompkins RG, Fischman AJ, et al. Autoradiographic method for quantitation of radiolabeled proteins in tissues using indium111. J Nucl Med. 1989; 30:1538-1545.

22. Rubin RH, Fischman AJ, Callahan RJ, et al. Ind-111-labeled nonspecific immunoglobülin scanning in detection of focal infection. $\mathrm{N}$ Engl J Med. 1989; 321: 935-940.

23. Bois $\mathrm{MH}$, de, Welling $M$, Verwey $C L$, et all. Tc99m-HIG accumulation in sinovial tissue of rats with adjuvant arthritis by binding to extracellular matrix proteins. Nucl Med Commun. 1996; 17:54-59.

24. Gungor F, Karayalcin B, Gultekin M, et al. Comparison of Tc-99m HIG and Ga-67 citrate in evaluation of bacterial abscess in a rat model. Ann Nuc Med. 1996; 10:79-83

25. Breedveld FC, van Kroonenburgh MJ, Camps JA, Feitsma HI, Markusse HM, Pauwels EK. Imaging of inflammatory arthritis with Tc99m labelled IgG.JNuc Med 1989;39:516-21

26. Kohn MD, Sassoon AA, Fernando ND. Classifications in Brief: Kellgren-Lawrence Classification of Osteoarthritis. Clin OrthopRelat Res. 2016 Aug;474(8):1886-93. doi: $10.1007 / \mathrm{s} 11999-016-4732-4$.

27. Cheng OT, Souzdalnitski D, Vrooman B, Cheng J. Evidence-based knee injections for the management of arthritis. Pain Med. 2012;13(6):740-53. doi: 10.1111/j.15264637.2012.01394. $x$.

28. Jüni $P$, Hari $R$, Rutjes $A W$, et al. Intra-articular corticosteroid for knee osteoarthritis. Cochrane Database Syst Rev. 2015; 22; (10):CD005328.

29. Pelletier JP 1, Martel-Pelletier J. Protective effects of corticosteroids on cartilage lesions and osteophyte formation in the Pond-Nuki dog model of osteoarthritis. Artrit Rheum. 1989 Feb; 32 (2): 181-93.

30. Bodick N, Williamson $T$, Strand V, et al. Local Effects Following Single and Repeat IntraArticular Injections of Triamcinolone Acetonide Extended-Release: Results from Three Nonclinical Toxicity Studies in Dogs. 
Rheumatol Ther. 2018 Dec;5(2):475-498. doi: 10.1007/s40744-018-0125-3.

31. Myers SL. Suppression of hyaluronic acid synthesis in synovial organ cultures by corticosteroid suspensions. Arthritis Rheum. 1985; 28(11):1275-82.

32. de Bois $\mathrm{MH}$, Arndt JW, Tak PP, et al. 99Tcmlabelled polyclonal human immunoglobulin $\mathrm{G}$ scintigraphy before and after intra-articular knee injection of triamcinolone hexacetonide in patients with rheumatoid arthritis. Nucl Med Commun. 1993;14(10):883-7

33. Raynauld JP, Buckland-Wright C, Koğuş R, Choquette D. Safety and Efficacy of LongTerm Intraarticular Steroid Injections in Osteoarthritis of the Knee. Arthritis \& $\begin{array}{llll}\text { Rheumatism 2003;48 (2): } \quad 370-377 \text { DOI } & \end{array}$ 10.1002/art. 10777

34. PG Conaghan, Hunter DJ, Cohen, SB, Kraus VB. Effects of a Single Intra-Articular Injection of a Microsphere Formulation of Triamcinolone Acetonide on Knee Osteoarthritis Pain: A Double-Blinded, Randomized, PlaceboControlled, Multinational Study. J Bone Joint Surg Am. 2018;18;100(8):666-677. doi: 10.2106/JBJS.17.00154.

35. Popma JW, Snel FW, Haagsma CJ, Brummelhuis-Visser $P$, Oldenhof HG. Comparison of 2 Dosages of Intraarticular Triamcinolone for the Treatment of Knee Arthritis: Results of a 12-week Randomized Controlled Clinical Trial.JRheumatol. 2015;42(10):1865-8. doi:
36. Palermo F, Boccaletto F, Paolin A, et al. Comparison of technetium-99m-MDP, technetium-99m-WBC and technetium-99mHIG in musculoskeletal inflammation. J Nucl Med. 1998;39(3):516-21.

37. Breedveld $\mathrm{FC} 1$, van Kroonenburgh MJ, Camps JA, Feitsma HI, Markusse HM, Pauwels EK. Imaging of inflammatory arthritis with technetium-99m-labeled IgG. J Nucl Med. 1989;30(12):2017-21

38. Jamar F, Manicourt DH, Leners N, Vanden Berghe M, Beckers C. Evaluation of disease activity in rheumatoid arthritis and other arthritides using 99mtechnetium labeled nonspecific human immunoglobulin. J Rheumatol. 1995;22(5):850-4.

39. De Bois $\mathrm{MH}$, Arndt JW, van der Velde EA, et al. 99mTc human immunoglobulin scintigraphy-a reliable method to detect joint activity in rheumatoid arthritis. J Rheumatol. 1992;19(9):1371-6. 